\title{
The case of Emma Eckstein
}

\section{John Launer}

One of the most bizarre acts of medical malpractice took place over a hundred years ago, and happens to be one of the best documented. This is because the two doctors involved - a surgeon and a physician - corresponded at length about it, and the physician's letters have been preserved. The case has important lessons for doctors, because it contains so many elements that still put patients at risk. These include idiosyncratic treatment, mistaking physical problems for psychological ones, negligence, blaming the patient, coverups, and flagrant sexism.

The main perpetrator, Wilhelm Fliess, was a successful ear, nose and throat surgeon, who practised in Berlin in the late nineteenth and early twentieth centuries. He had a wide range of medical interests, including biorhythms and the phenomenon of bisexuality, which he believed to be universal. He was one of the first doctors to apply topical cocaine to the nasal mucous membrane, and was interested to find that his patients often improved in their general health as a result. On the basis of this, he conceived the idea that the nose was a far more important organ than had ever been recognised, and was intimately connected with the heart, respiration, digestion and the genito-urinary system, along with mental well-being. In a monograph published in 1892, he described a condition he called the "nasal reflex neurosis". ${ }^{1} \mathrm{He}$ argued that nasal infections or alterations in vasomotor function could lead, among other things, to menstrual disorders, infertility and miscarriages. Equally, he claimed, the therapeutic application of cocaine to specific areas of the nasal mucosa could be used to remedy these.

Fliess had a good friend a few hundred miles away in Vienna who was a physician, specialising in neurology. The friend was later to become well known, but was struggling at the time to make a living in private practice, and had decided to specialise in some poorly understood disorders, including "neurasthenia" and "hysteria" - roughly the equivalent of what we would now term chronic fatigue and somatisation disorder.

Correspondence to: Dr John Launer, Faculty Development, Health Education England, Stewart House, 32 Russell Square, London WC1B 5DN, UK: john.launer@nwl.hee.nhs.uk
He had come up with his own explanations for these conditions, believing these to include masturbation, coitus interruptus, and sexual abuse in childhood. He was attracted to Fliess's idea of nasal reflex neurosis, and curious about how these might apply to mental disorders. Among his patients was a beautiful young woman named Emma Eckstein, who appears to have suffered from irregular, heavy or painful periods, accompanied by difficulty in walking and sexual problems. He introduced her to Fliess, who came to Vienna in early 1895 to treat her.

\section{HORRIFIC COMPLICATIONS}

Emma Eckstein was not Fliess's only patient on that visit. He also treated the neurologist himself, applying cocaine to his nose, in order to treat palpitations and breathlessness: these were probably of psychological origin, or due to excess nicotine. In Emma's case, Fliess did considerably more. He decided that the best treatment would be to remove one of her turbinate bones surgically. Soon after Fliess left Vienna, Emma began to suffer some horrific post-operative complications, including haemorrhages and a discharge with a disgusting smell. Her neurologist called in a senior local specialist, who inserted a drain. This was ineffective, and a second surgeon named Rosanes was called in. The neurologist wrote afterwards to Fliess, to explain what happened:

"Rosanes cleaned the area surrounding the opening, removed some sticky blood clots, and suddenly pulled at something like a thread, and kept on pulling. Before either of us had time to think, at least half a meter of gauze had been removed from the cavity. The next moment came a flood of blood. The patient turned white, her eyes bulged, and she had no pulse. Immediately thereafter, however, he again packed the cavity with fresh iodoform gauze and the haemorrhage stopped. It lasted about half a minute, but this was enough to make the poor creature, whom by then we had lying flat, unrecognisable ... I felt sick. After she had been packed, I fled to the next room, drank a bottle of water, and felt miserable. [My wife] then brought me a small glass of cognac and I became myself again." 2

This life-threatening episode - entirely the consequence of Fliess mislaying half a

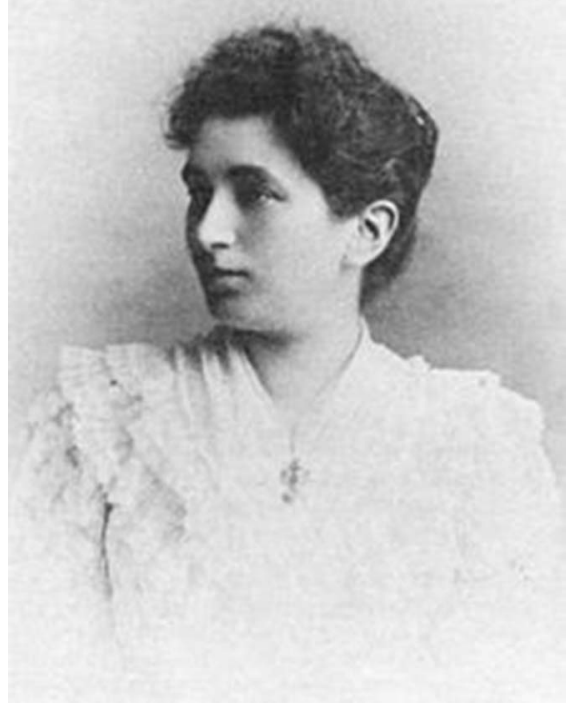

Figure Emma Eckstein.

metre of surgical gauze in Emma's nose was only the first of her trials. A month later, after partial removal of some packing, she had a further massive haemorrhage. "Within half a minute", the neurologist wrote this time "she would have bled to death." Over the next few weeks, with the help of morphine and with repeated re-packing each time she bled, Emma gradually recovered. Fliess continued to send advice from a distance, which the Viennese surgeons prudently ignored. Meanwhile, the neurologist sent letters to his friend to reassure him that the oversight with the gauze was a "mishap" that could happen to anyone. While intimating that the surgeons in Vienna all took a poor view of Fliess's skills, he offered his own admiration. "For me," he wrote, "you remain the physician, the type of man, into whose hands one confidently puts one's life and that of one's family." As far as the patient was concerned, he wrote: "she did not change her attitude toward either one of us: she honours your memory, beyond the unwelcome accident."

\section{OUTLANDISH IDEAS}

The neurologist involved in this case, it is only fair to reveal, was Sigmund Freud. His close friendship with Fliess took place in the years just before he developed the theory of psychoanalysis, for which he became world famous. After Emma Eckstein's operation, Freud went on treating her psychologically. She continued to have abnormal menstrual bleeding, which he confidently attributed to unrequited sexual longing - although she may in fact 
have had a congenital bleeding disorder, as well as fibroids, for which she eventually had a hysterectomy.

By the time Freud's career finally took off, he and Fliess had distanced themselves from each other, although Freud never explicitly repudiated his friend's outlandish ideas or his surgical treatment. Apologists have argued that Fliess's notions were no more offbeat than many others from that time, but this is at odds with contemporary reviews of his publications, and comments from several other surgeons who saw Emma in the course of her recovery. These make it clear that he was regarded as just as eccentric and dangerous then as he would be nowadays although no steps were ever taken to remove him from practice. Later on, Freud destroyed the letters he had from Fliess. He also wished to have Fliess's side of the correspondence suppressed, but failed. Some years after Freud's death, his daughter Anna and two of her colleagues published a selection of them. They made it clear how eccentric Fliess's ideas were, but they expunged every mention of Emma Eckstein. It was only in 1985, some ninety years after the original episode, that the letters were reproduced in full, in an edition by the renegade psychoanalyst Jeffrey Masson. The revelations about Eckstein were shocking in their own right, but Masson added more fuel to the fire by claiming that Freud had known but concealed the fact that Emma Eckstein, and many of his other women patients, were probably victims of incest in the first place. ${ }^{34}$

All this noisy drama, sadly, was far too late to bring any redress to Emma Eckstein. She worked for several years as a psychoanalyst herself, but withdrew from the world for the last twenty years of her life. Her once beautiful face remained disfigured, with the nasal bone chiselled away, and one side caved in. She spent all her days on a couch, never left her room, and could not walk. She died from a stroke in 1924, at the age of 59.

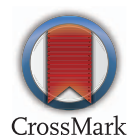

To cite Launer J. Postgrad Med J 2016;92:59-60.

Postgrad Med J 2016;92:59-60.

doi:10.1136/postgradmedj-2015-133867

\section{REFERENCES}

1 Freud S. The Origins of Psycho-Analysis: Letters to Wilhelm Filess, Drafts and Notes, 1887-1902. NY: Basic Books, 1954.

2 Masson JM, ed. The complete letters of Sigmund Freud to Wilhelm Fliess, 1887-1904. Cambridge: Harvard University Press, 1985.

3 Masson JM. The Assault on Truth: Freud's Suppression of the Seduction Theory. New York, NY: Farrar, Straus and Giroux, 1984.

4 Malcolm J. In the Freud Archives. New York, NY: NRYB Classics, 2002. 